\title{
A Case of Removal of Multiple Submandibular Gland and Duct Stones by Cervical Incision Approach
}

\author{
Byeong Min Lee ${ }^{1}$, Jin Hyun Seo ${ }^{1}$, and Seung Hoon Woo ${ }^{2}$ D \\ ${ }^{1}$ Department of Otorhinolaryngology-Head and Neck Surgery, Gyeongsang National University, Jinju; and \\ ${ }^{2}$ Department of Otorhinolaryngology-Head and Neck Surgery, Dankook University School of Medicine, Cheonan, Korea
}

\author{
경부 절개 접근을 통한 악하선 및 악하선관 다발성 타석 제거 1 예 \\ 이병민 ${ }^{1} \cdot$ 서진현 $^{1} \cdot$ 우승훈 $^{2}$ \\ 경상대학교 의학전문대학원 이비인후과학교실, ${ }^{1}$ 단국대학교 의과대학 이비인후과학교실 ${ }^{2}$
}

\author{
Received December 6, 2018 \\ Revised January 18, 2019 \\ Accepted January 30, 2019 \\ Address for correspondence \\ Seung Hoon Woo, MD \\ Department of Otorhinolaryngology \\ Head and Neck Surgery, \\ Dankook University \\ School of Medicine, \\ 201 Manghyang-ro, Dongnam-gu, \\ Cheonan 31116, Korea \\ Tel $+82-41-550-1781$ \\ Fax $+82-41-550-7837$ \\ E-mail lesaby@hanmail.net
}

A calcified structure blocking the flow of saliva into the mouth is a major cause of salivary dysfunction. If a stone is detected, the goal of treatment would be to remove it. Furthermore, the fundamental treatment for preventing recurrence, although depending on the location and size of the stone, is salivary gland resection. The submandibular gland duct and hilum stone is usually removed by transoral approach. If there are multiple stones in the submandibular gland and the duct, it would be necessary to carry out resection of submandibular gland, using the intra-oral approach. We recently experienced a case of multiple stone in the submandibular gland and the duct in a 73-year-old man, who presented with the right submandibular area swelling after meals. We removed the submandibular gland and duct stone without intra-oral approach and present this case with a review of the literature.

Korean J Otorhinolaryngol-Head Neck Surg 2019;62(11):647-50

Key Words Sialolithiasis · Submandibular gland · Whartons duct.

\section{서 론}

타석증(sialotithiasis)은 성인의 침샘에서 발생하는 가장 흔한 질환 중 하나이며 매년 1000 명의 성인 중 12 명이 이 질 환을 않고 있고 남성이 여성보다 많은 것으로 알려져 있다. 가장 흔한 임상 증상으로는 타석이 있는 침샘 부위의 호전과 악화를 반복하는 통증과 부종이며 특징적으로 식후에 발생 하는 경우 의심할 수 있다. 보존적인 치료에도 반복적으로 재발하게 된다면 수술적 제거가 필요하고 발견된 타석은 제 거하는 것이 원칙이며 그 방법은 타석의 위치에 따라 다르다.

악하선 타석증에서 관 내 타석일 경우 경구강 접근법을 통 한 타석 제거술이 가능하며 악하선문이나 악하선 내의 타석

This is an Open Access article distributed under the terms of the Creative Commons Attribution Non-Commercial License (https://creativecommons.org/licenses/by-nc/4.0) which permits unrestricted non-commercial use, distribution, and reproduction in any medium, provided the original work is properly cited.
일 경우 경부 접근을 통한 악하선 절제술이 시행되고 있다. 경부 절개를 통한 악하선 절제술은 보존해야 하는 주위 혈 관과 신경의 확인이 용이하나 절개 부위 상처로 인한 미용상 의 문제와 안면신경 하악분지의 손상으로 인한 안면마비 가 능성이 있어 가능하다면 경구강 접근법을 통한 타석 제거술 이 선호되고 있다. ${ }^{2}$ 경구강 접근법을 통한 타석 제거술의 경 우 이런 단점을 보완할 수 있으나 다른 합병증들을 발생시킬 수 있다. 경구강 접근법 시 악하선관의 염증(sialodochitis)이 동반되거나 수술 시야가 좋지 않을 경우에는 설하선의 제거 가 필요할 수 있고 이는 추가적인 출혈 발생과 함께 완전 절 제가 되지 않을 경우 점액낭종의 발생 가능성이 있으며 절제 과정에서 설신경이나 악하선관의 손상을 줄 수 있으므로 주 의를 요한다. 악하선관과 악하선 내 모두 타석이 있다면 경 부 절개를 통한 악하선 절제술과 함께 경구강 접근을 통한 관 내 타석 제거술이 필요하다. 저자들은 최근 악하선관과 
악하선 내에 함께 발생한 다발성 타석증 환자에 대해 경부 절개만을 통한 악하선 절제술을 시행함과 동시에 악하선관 내의 타석을 함께 제거한 증례를 경험하였기에 문헌 고찰과 함께 보고하는 바이다.

\section{증 례}

73세 남자 환자가 수개월 전부터 반복되는 식후 우측 턱밑 의 통증을 동반한 붓기를 주소로 외래 내원하였다. 환자는 과거력상 당뇨가 있었으며 왼쪽 다리의 폐쇄성 죽상동맥경 화증으로 스텐트 삽입술 시행력이 있고 조기위암으로 전복 강경하 원위부 위절제술 받은 병력이 있었다. 외래에서 시행 한 신체검사상 우측 악하선이 좌측보다 두드러지게 촉지되 었으며 가벼운 압통이 동반되었으나 붓기는 관찰되지 않았 다. 구개저(mouth floor)의 두손촉진(bimanual palpation)을 시행하여 악하선관을 따라 여러 개의 타석이 촉지됨을 확인 하였으며 악하선관 타석증과 이에 동반된 악하선염 의심하 에 CT를 시행하였다. 시행한 CT상 우측 악하선문 부터 와튼 관 입구(wharton's duct orifice)까지 도관을 따라 존재하는 $0.6 \mathrm{~cm}$ 이하의 다발성의 타석을 확인하였으며 악하선 안에 도 타석이 존재하는 것을 확인하였다(Fig. 1). 따라서 수술적
제거를 계획하였다.

다발성 타석은 악하선 내부와 악하선관 내에 모두 존재하 였으며 악하선 내에 존재하는 타석으로 인해 악하선 절제술 이 불가피하였다. 이에 경부 절개를 통한 우측 악하선 절제 술을 시행하고 경구강 접근법을 통한 관 내 타석 제거도 필 요하였다. 그러나 저자들은 경구강 접근법을 통한 타석 제거 시 발생할 수 있는 합병증을 예방하고 구강 내의 절개로 인 한 환자의 불편함을 방지하고자 경부 절개만을 통해 악하선 절제술과 악하선 관 내 타석 제거를 함께 시행할 것을 고려 하였다. 경부 절개를 통한 악하선 절제술을 먼저 시행하되 악하선관 결찰 전에 악하선관에 절개를 가하고 와튼관 입구 (wharton's duct orifice)로부터 주사기를 통한 물관류(water irrigation)를 이용해 악하선관 절개 부위를 통한 관 내 타석 제거를 계획하였다. 경부 절개를 통해 우측 악하선을 박리하 여 노출시킨 후 악하선관 내의 다발성 타석을 확인하였다 (Fig. 2). 이후 악하선관에 평행하게 절개를 가하여 확인되는 타석을 먼저 제거하였으며 우측 구개저에서 타석을 촉지하고 실린지에 연결한 경정맥 카테터를 이용하여 와튼관 입구를 통해 생리식염수를 주입하여 악하선관 절개 부위로 흘러나 오는 타석을 확인하고 모두 제거하였다(Fig. 2). 이후 수차례 물관류를 통해 관 내 세척을 시행하였으며 탐침(probe)을 이
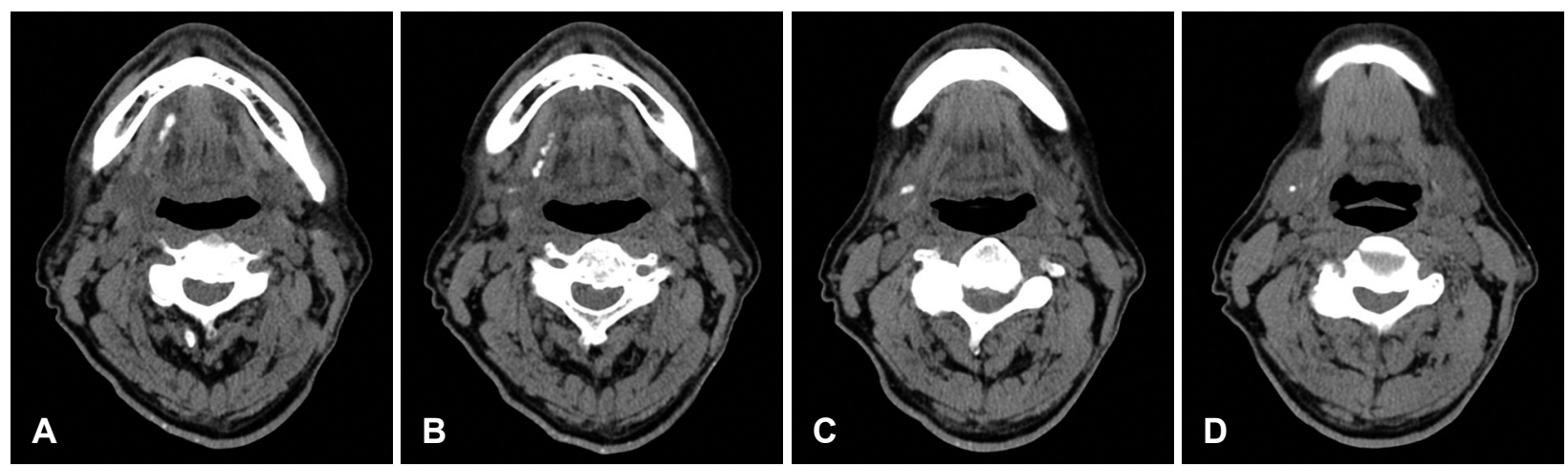

Fig. 1. CT scan shows multiple stone in right submandibular gland and submandibular gland duct. Multiple stone at distal portion of duct (A). Multiple stons at mid portion of duct (B). Multiple stone at hilum (C). Multiple stone in gland (D).
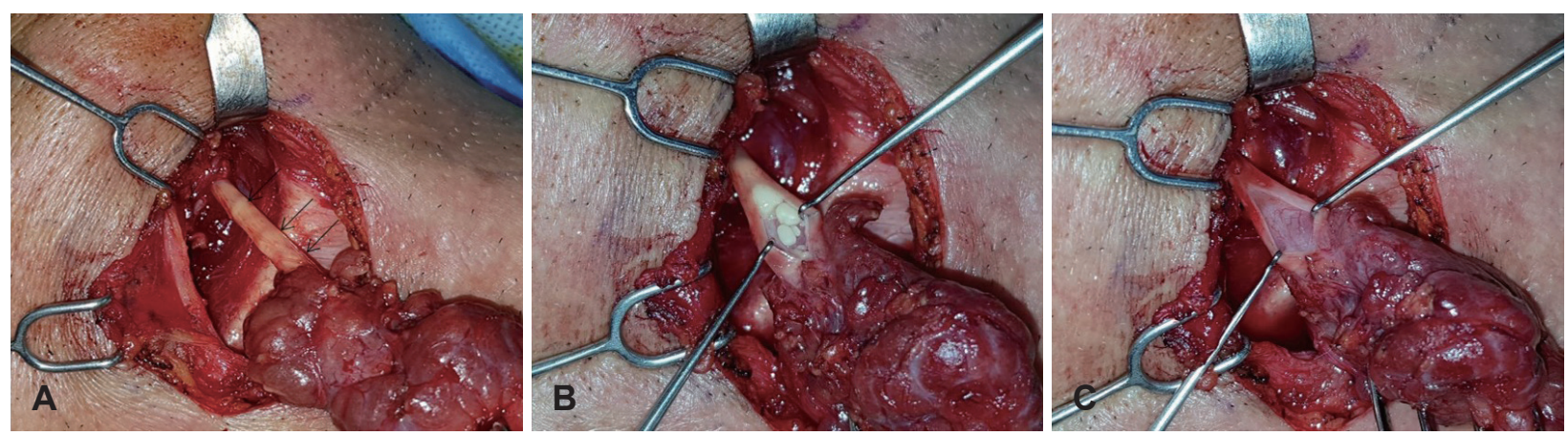

Fig. 2. This figures show dissected submandibular gland before duct ligation by cervical incision approach. Multiple stone in submandibular gland duct (arrows: stone) (A). Stones are seen in the incision in parallel with the submandibular gland duct (B). An empty ductal lumen after all the stones are removed (C). 


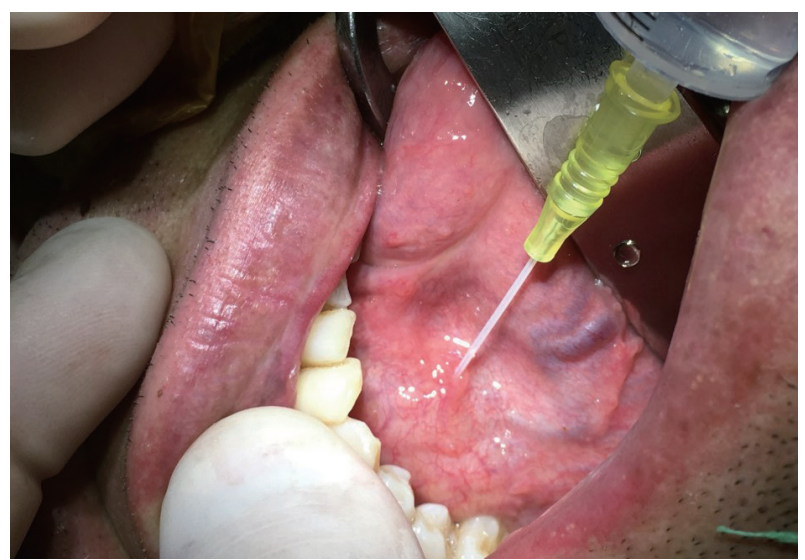

Fig. 3. Normal saline is injected using intravenous catheter through the wharton's duct orifice. We could then remove the stones from duct incision site.

용해 도관 내를 통과시켜 남아있는 타석이 없음을 확인하였 고 이후 악하선관을 결찰하고 악하선을 제거하였다(Figs. 3 and 4).

수술 후 다음날 악하선 관 내 남아 있는 타석의 유무 및 수술 부위 삼출물의 존재 여부를 확인하기 위해 초음파를 시행하였으며 잔여 타석이나 삼출물은 확인되지 않아 모든 타석이 제거되었음을 확인하였다. 전체 악하선관 내 존재했 던 타석은 총 10 개였으며 이 타석들은 악하선관을 따라 일 렬로 위치하고 있었고, 타석 제거 후 환자의 불편은 사라졌 다. 현재 외래 경과 관찰 중이다.

\section{고 찰}

타석증(sialolithiasis)은 소타액선을 제외한 침샘 질환의 $50 \%$ 이상을 차지하며 급성, 만성 감염의 가장 흔한 원인이 다. ${ }^{3-6)}$ 침샘의 위치에 따른 타석의 발생 빈도가 다르며 $80 \%$ 이상이 악하선 또는 악하선관에서 나타나고 이하선은 약 $6 \%$, 설하선과 소타액선에서 $2 \%$ 정도로 보고되고 있다. ${ }^{6.7)}$ 악 하선에 호발하는 이유는 타액의 조성이 다른 침샘보다 알칼 리성이며 점도가 높고 인산칼슘의 농도가 높을 뿐만 아니라 중력에 반하는 도관의 주행과 좁은 입구를 가지는 해부학적 인 구조로 인해 타액이 쉽게 정체되기 때문이다. 대부분의 환자들은 하나의 타석을 가지고 있으며 이하선 타석증의 $32 \%$, 악하선 타석증의 $22 \%$ 에서 두 개 이상의 타석이 발견되 었다는 보고가 있고 양측 타석증의 경우는 $2.2 \%$ 로 드물다고 알려져 있다. ${ }^{8,9)}$

악하선관 내의 타석은 경구강 접근법을 통해 타석 제거술 을 시행해 볼 수 있으나 악하선문이나 악하선 내 타석에 대 해서는 경구강 접근법 시 수술 시야가 좁고 접근하기 어려워 악하선 절제술이 주로 이용되어 왔다. 따라서 본 증례와 같

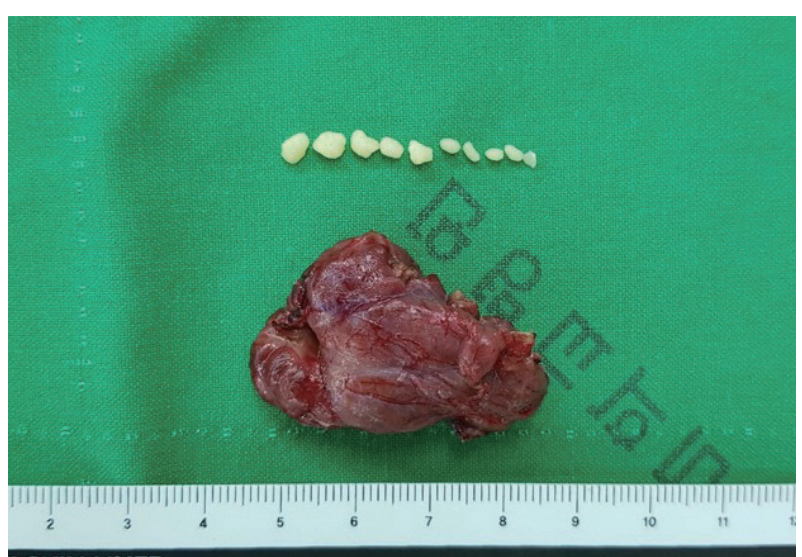

Fig. 4. Resected submandibular gland and removed stones.

이 악하선 및 악하선관 내의 다발성 타석이 있을 경우 경부 절개를 통한 악하선 절제술과 경구강 접근법을 통한 타석 제 거술이 함께 필요할 수 있다. 악하선문 타석의 경구강 접근 법을 통한 제거술의 성공률이 $86.7 \%$ 까지 보고되고 있으나 구개저의 후부 점막에 절개를 넣고 타석을 제거하는 과정에 서 시야가 좁고 박리가 어렵다면 설하선의 제거를 고려하게 된다. 불완전한 설하선의 절제로 인한 점액낭종의 발생은 $1 \sim 2 \%$ 로 보고되고 있으며 반복되는 염증으로 인한 유착과 출혈은 설신경의 손상과 같은 합병증을 발생시킬 수 있고 $1 \%$ 내외로 보고되고 있다. ${ }^{10,11)}$ 또한 타석을 제거하기 위해 경 구강 접근 시 절개된 악하선관이 막히거나 유착이 되는 것 을 방지하기 위해 도관 성형술(sialodochoplasty)을 시행하 는데 이는 수술 시간을 연장시키며 향후 악하선관이 다시 막 히는 문제점들도 나타난다. ${ }^{12)}$ 따라서 경부와 구강을 통한 두 가지 접근법을 동시에 사용한다면 수술 시간의 증가와 추가 절개로 인한 환자의 불편 증가 등 향후 여러 문제점들도 예 상할 수 있기에 가능하다면 경부 절개만을 통해 타석을 제거 하는 방법을 선택하였다.

우선 악하선을 제거하기 위해 경부 절개를 가하고 악하선 을 노출시킨 후 악하선관 만이 연결된 상태로 주변 조직과의 박리를 진행하였다. 이후 이 악하선관에 수평하게 절개를 가 하여 보이는 타석을 제거하였고, 추가로 남아있을 타석을 제 거하기 위해 수 회의 생리식염수 세척과 탐침을 통해 타석이 남아있지 않은 것을 확인하였다. 이런 방법을 사용한 이유는 악하선을 악하선관에서 완전 제거 후 절단된 도관을 통해 타석을 제거하고자 한다면 악하선관의 탄성으로 인해 악하 선관이 구강 쪽으로 수축되면서 타석의 제거가 어려울 수 있 기 때문이다. 따라서 악하선을 완전 절제하지 않고 도관과 연 결된 상태로 도관에 절개를 가하여 타석을 제거한다면 이런 어려움을 방지할 수 있으며 또한 보이지 않는 관 내 타석에 대해서는 와튼관 입구를 통한 생리식염수 세척과 함께 탐침 
을 이용한 탐색으로 완전 제거를 시행할 수 있다. 본 증례에 서는 이하선 내 1 개의 타석과 함께 도관 내 10 개의 타석을 제거하였으며 경구강 접근법을 통해 발생할 수 있는 합병증 을 예방하였고 도관 성형술도 필요하지 않았다.

악하선 타석증에 대한 다양한 치료법이 시도되고 있으며 환자의 불편 감소와 합병증을 줄이는 연구들이 진행되고 있 다. 성공률이 $60 \%$ 정도로 보고되고 있는 체외충격파쇄석술 (extracorporeal shock wave lithotripsy)도 있으며 90년대부 터 타액선을 보존하는 최소 침습적인 타액관 내시경술이 비 약적인 발전을 이루어 타석 제거에 있어서 적응증에만 해당 한다면 80 90\%까지 성공률을 보고하고 있다. ${ }^{13)}$ 뿐만 아니 라 증상 없는 타석의 발견이나 초기 타석의 발견, 염증 후의 타액선관 협착이나 막힘, 해부학적 변이의 진단과 치료, 자가 면역 질환, 치료 후나 조대술 후 타액선관의 관찰을 위해서 도 이용되고 있으므로 그 유용성은 앞으로 더욱 커질 것으 로 보인다. ${ }^{14)}$ 그러나 현재까지는 내시경의 직경과 조작의 한 계로 인해 타석이 타액선관의 개구부에서 가깝게 위치한 경 우나 크기가 $5 \mathrm{~mm}$ 이하인 경우, 관내 운동성이 있는 경우에 이용할 것을 권고하고 있다. ${ }^{15)}$ 결국 악하선 내에 발생한 타석 에 대해서는 경부 접근법을 통한 악하선 제거술 이외에는 아 직 다른 방법이 마련되고 있지 않다. ${ }^{16)}$ 따라서 가능한 절개를 적게 하고 합병증의 발생을 줄이는 노력들이 필요해 보이며 본 증례와 같은 경우 악하선관과 악하선 내 발생한 다발성 타석에 대해 경구강 접근법 없이 경부 접근 만을 통해 모두 제거가 가능하였으므로 유용한 타석 제거법으로 사료되어 문헌 고찰과 함께 보고하는 바이다.

\section{ORCID}

Seung Hoon Woo https://orcid.org/0000-0001-7560-1140

\section{REFERENCES}

1) Leung AK, Choi MC, Wagner GA. Multiple sialoliths and a sialolith of unusual size in the submandibular duct: A case report. Oral Surg Oral Med Oral Pathol Oral Radiol Endod 1999;87(3):331-3.

2) Jeong HS, Baek CH, Son YI, Chung KW, Lee DK, Kim JH, et al. Management of calculi in the hilum of submandibular gland: Intraoral removal with marsupialization of the duct. Korean $\mathrm{J}$ Otorhinolaryngol-Head Neck Surg 2005;48(8):1034-8.

3) Siddiqui SJ. Sialolithiasis: An unusually large submandibular salivary stone. Br Dent J 2002;193(2):89-91

4) Seldin HM, Seldin SD, Rakower W. Conservative surgery for the removal of salivary calculi. Oral Surg Oral Med Oral Pathol 1953; 6(5):579-87.

5) Epker BN. Obstructive and inflammatory diseases of the major salivary glands. Oral Surg Oral Med Oral Pathol 1972;33(1):2-27.

6) Lustmann J, Regev E, Melamed Y. Sialolithiasis. A survey on 245 patients and a review of the literature. Int J Oral Maxillofac Surg 1990;19(3):135-8.

7) McKenna JP, Bostock DJ, McMenamin PG. Sialolithiasis. Am Fam Physician 1987;36(5):119-25.

8) Levy DM, Remine WH, Devine KD. Salivary gland calculi. Pain, swelling associated with eating. JAMA 1962;181:1115-9.

9) Kim JP, Park JJ, Son HY, Woo SH. An unusual case of bilateral submandibular sialolithiasis. J Med Cases 2012;3(2);106-9.

10) Nahlieli O. Complications of traditional and modern therapeutic salivary approaches. Acta Otorhinolaryngol Ital 2017;37(2):142-7.

11) Park HS, Pae SY, Kim KY, Chung SM, Kim HS. Intraoral removal of stones in the proximal submandibular duct: Usefulness of a surgical landmark for the hilum. Laryngoscope 2013;123(4):934-7.

12) Woo SH, Kim JP, Kim JS, Jeong HS. Anatomical recovery of the duct of the submandibular gland after transoral removal of a hilar stone without sialodochoplasty: Evaluation of a phase II clinical trial. Br J Oral Maxillofac Surg. 2014;52(10):951-6.

13) Rotnágl J, Zavázalová Š, Vorobiov $\mathrm{O}$, Astl J. Sialendoscopy and combined minimally invasive treatment for large parotid stones. Biomed Res Int 2016;2016:1354202.

14) Choi JS, Lim JY, Kim YM. Sialendoscopy. Korean J OtorhinolaryngolHead Neck Surg 2011;54(12):819-27.

15) Kim TW, Kang JH, Jeong HS, Son YI, Baek CH. Sialendoscopy for salivary duct stone. Korean J Otolaryngol 2004;47(7):655-60.

16) Nahlieli O, Shacham R, Bar T, Eliav E. Endoscopic mechanical retrieval of sialoliths. Oral Surg Oral Med Oral Pathol Oral Radiol Endod 2003;95(4):396-402. 